\title{
Haemodynamic correlates and prognostic significance of serum uric acid in adult patients with Eisenmenger syndrome
}

\author{
H Oya, N Nagaya, T Satoh, F Sakamaki, S Kyotani, M Fujita, N Nakanishi, K Miyatake
}

\begin{abstract}
Objective-To assess haemodynamic correlates and prognostic significance of serum uric acid in adult patients with Eisenmenger syndrome.

Design-Retrospective observational study.

Setting-Tertiary referral centre.

Patients-94 adult patients with Eisenmenger syndrome who were diagnosed between September 1982 and July 1998.

Main outcome measures-Serum uric acid was measured in all patients, together with clinical and haemodynamic variables related to mortality.

Results-Serum uric acid was raised in patients with Eisenmenger syndrome compared with age and sex matched control subjects $(7.0 v 4.7 \mathrm{mg} / \mathrm{dl}, \mathrm{p}<0.0001)$ and increased in proportion to the severity of New York Heart Association functional class. Serum uric acid was positively correlated with mean pulmonary arterial pressure $(r=0.30, \mathrm{p}=0.0052)$ and total pulmonary resistance index $(r=0.55, \mathrm{p}<0.0001)$, and negatively correlated with cardiac index $(r=-0.50$, $\mathrm{p}<0.0001)$. During a mean follow up period of 97 months, 38 patients died of cardiopulmonary causes. Among various clinical, echocardiographic, and laboratory variables, serum uric acid remained predictive in multivariate analysis. Kaplan-Meier survival curves based on median serum uric acid showed that patients with high values had a significantly worse survival rate than those with low values (log-lank test: $p=0.0014$ in male patients, $p=0.0034$ in female patients). Conclusions-Serum uric acid increases in proportion to haemodynamic severity in adult patients with Eisenmenger syndrome and is independently associated with long term mortality. (Heart 2000;84:53-58)
\end{abstract}

Keywords: Eisenmenger syndrome; prognosis; uric acid; haemodynamics

Eisenmenger syndrome is characterised by raised pulmonary vascular resistance and reversed or bidirectional shunting through a congenital systemic to pulmonary circulatory connection. ${ }^{1}$ As the life expectancy of patients with this syndrome is $20-30$ years, the number of affected individuals surviving into adult life is continually increasing. ${ }^{2}{ }^{3}$ Nevertheless, some patients are refractory to medical treatment, and these ultimately develop cardiac dysfunction and die. ${ }^{45}$ Thus an accurate assessment of disease severity and the ability to predict the likelihood of death are important factors in making therapeutic decisions in adult patients with Eisenmenger syndrome.

Serum uric acid, the final product of purine degradation, has been shown to be increased in hypoxic states such as chronic heart failure, ${ }^{67}$ cyanotic congenital heart disease, ${ }^{8}$ and chronic obstructive lung disease. ${ }^{9-11}$ Hyperuricaemia may result from either overproduction or impaired excretion of uric acid. ${ }^{12}$ Serum uric acid concentration has recently been reported to have a strong, independent association with the severity of symptoms and mortality in patients with chronic or acute heart failure ${ }^{1314}$ or primary pulmonary hypertension. ${ }^{15}$ However, little information is available on the clinical and prognostic significance of serum uric acid in adult patients with Eisenmenger syndrome. Our aim in this study was first, to assess the association between serum uric acid concentration and the severity of Eisenmenger syndrome, and second, to investigate whether mortality in adult patients with Eisenmenger syndrome can be predicted by measuring serum uric acid.

\section{Methods}

STUDY PATIENTS

One hundred and seven adult patients were diagnosed as having Eisenmenger syndrome at our institute between September 1982 and July 1998. Four were excluded because of renal dysfunction (serum creatinine $>175 \mu \mathrm{mol} / \mathrm{l}$ ). Follow up data were obtained by review of patients' records, telephone interviews with patients or next of kin, and personal communication with the patients' physicians. Nine patients who could not be contacted by any means were excluded from the study. The remaining 94 patients (34 male and 60 female, mean age 37 years, range 15 to 67) were enrolled in the study.

Eisenmenger syndrome was defined as the presence of severe pulmonary hypertension and cyanosis caused by right to left shunting of blood through a systemic to pulmonary circulatory connection, ${ }^{1}$ confirmed at cardiac catheterisation. The cause was atrial septal defect in 48 patients, ventricular septal defect in 23, persistent arterial duct in 14, and other pathology in nine. Forty two patients were classified as being in New York Heart Association (NYHA) functional class II, 46 patients in class III, and six patients in class IV. Six 
Table 1 Baseline characteristics in adult patients with Eisenmenger syndrome according to survival

\begin{tabular}{|c|c|c|c|}
\hline Variables & $\begin{array}{l}\text { Survivors } \\
(n=56)\end{array}$ & $\begin{array}{l}\text { Non-survivors } \\
(n=38)\end{array}$ & $p$ Value \\
\hline \multicolumn{4}{|l|}{ Demographics } \\
\hline Age (years) & $37(2)$ & $37(2)$ & 0.9615 \\
\hline Sex, male/female (n) & $17 / 39$ & $17 / 21$ & 0.1120 \\
\hline $\mathrm{BMI}\left(\mathrm{kg} / \mathrm{m}^{2}\right)$ & $18.1(0.3)$ & $18.4(0.6)$ & 0.6202 \\
\hline \multicolumn{4}{|l|}{ Primary defect $(\mathrm{n})$} \\
\hline ASD & 29 & 19 & 0.9642 \\
\hline VSD & 16 & 7 & 0.3077 \\
\hline PDA & 8 & 6 & 0.7609 \\
\hline Other & 3 & 6 & 0.0816 \\
\hline \multicolumn{4}{|l|}{ NYHA functional class (n) } \\
\hline II & 35 & 7 & 0.0001 \\
\hline III & 21 & 25 & 0.0061 \\
\hline IV & 0 & 6 & 0.0017 \\
\hline \multicolumn{4}{|l|}{ Laboratory findings } \\
\hline Packed cell volume (\%) & $46(1)$ & $49(2)$ & 0.2624 \\
\hline Mean corpuscular volume (fl) & $91.4(0.8)$ & $89.0(1.2)$ & 0.1256 \\
\hline Serum creatinine $(\mu \mathrm{mol} / \mathrm{l})$ & $69.8(2.7)$ & $82.2(3.5)$ & 0.0081 \\
\hline Serum total cholesterol $(\mathrm{mmol} / \mathrm{l})$ & $4.20(0.13)$ & $4.40(0.16)$ & 0.3155 \\
\hline Triglycerides $(\mathrm{mmol} / \mathrm{l})$ & $1.04(0.07)$ & $0.96(0.06)$ & 0.7183 \\
\hline Fasting blood glucose $(\mathrm{mmol} / \mathrm{l})$ & $4.6(0.1)$ & $4.4(0.1)$ & 0.0724 \\
\hline Serum uric acid $(\mathrm{mg} / \mathrm{dl})$ & $5.9(0.2)$ & $8.7(0.4)$ & $<0.0001$ \\
\hline \multicolumn{4}{|l|}{ Haemodynamic variables } \\
\hline $\mathrm{mSAP}(\mathrm{mm} \mathrm{Hg})$ & $84(2)$ & $82(3)$ & 0.1915 \\
\hline $\mathrm{mPAP}(\mathrm{mm} \mathrm{Hg})$ & $60(3)$ & $69(4)$ & 0.0396 \\
\hline $\mathrm{CI}\left(1 / \mathrm{min} / \mathrm{m}^{2}\right)$ & $2.9(0.1)$ & $2.4(0.1)$ & 0.0059 \\
\hline TPRI (Wood units $/ \mathrm{m}^{2}$ ) & $23(1)$ & $31(2)$ & 0.0009 \\
\hline $\mathrm{RAP}(\mathrm{mm} \mathrm{Hg})$ & $3(1)$ & $5(1)$ & 0.0165 \\
\hline PCWP (mm Hg) & $8(1)$ & $6(2)$ & 0.3911 \\
\hline \multicolumn{4}{|l|}{ Gas exchange $(\%)$} \\
\hline Arterial oxygen saturation & $87(1)$ & $83(1)$ & 0.0105 \\
\hline Mixed venous oxygen saturation & $65(1)$ & $60(1)$ & 0.0024 \\
\hline \multicolumn{4}{|l|}{ Treatment/procedures $(\mathrm{n})$} \\
\hline Diuretics & 13 & 20 & 0.0019 \\
\hline Digitalis & 26 & 25 & 0.0962 \\
\hline Vasodilators & 7 & 4 & 0.8285 \\
\hline Anticoagulant agents & 7 & 7 & 0.3771 \\
\hline Venesections & 2 & 8 & 0.0054 \\
\hline
\end{tabular}

Values are mean (SEM) except for numerical data.

ASD, atrial septal defect; BMI, body mass index; CI, cardiac index; mPAP, mean pulmonary arterial pressure; mSAP, mean systemic arterial pressure; NYHA, New York Heart Association; PCWP, pulmonary capillary wedge pressure; PDA, persistent arterial duct; RAP, right atrial pressure; TPRI, total pulmonary resistance index; VSD, ventricular septal defect.

patients had additional risk factors that are said to influence the serum uric acid level, ${ }^{16-20}$ including hyperlipidaemia in four and diabetes mellitus in two. Diuretics had been prescribed in 33 patients.

Fifty age and sex matched healthy volunteers (19 male and 31 female, mean age 39 years, range 16 to 65 ) served as controls. None of the control subjects had a history of cardiovascular, renal, respiratory, hepatic, or metabolic disease, and none was taking any drugs. All subjects gave their informed consent.

HAEMODYNAMIC STUDIES

Cardiac catheterisation was performed in all patients when they were in a stable condition during a hospital admission. Baseline haemodynamic variables measured included mean pulmonary arterial pressure, mean right atrial pressure, pulmonary capillary wedge pressure, and systemic arterial pressure. Cardiac output was measured by the Fick principle, ${ }^{21}$ and the cardiac index was calculated in relation to body surface area. Total pulmonary resistance index was calculated by dividing mean pulmonary arterial pressure by the cardiac index.

BLOOD SAMPLING FOR URIC ACID MEASUREMENT Venous blood was drawn after an overnight fast within 10 days of the first diagnostic catheterisation for measurement of serum uric acid, creatinine, triglycerides, total cholesterol, fast- ing blood glucose, and packed cell volume. Serum uric acid concentration was determined by the uricase-peroxidase method. ${ }^{22}$

SERIAL URIC ACID VALUES

We were able to assess serial uric acid values in 45 patients. Of these 45 patients, 20 (three male and 17 female, mean age 38 years, range 15 to 67: exacerbation group) showed worsening of NYHA functional class when their serum uric acid was re-evaluated after a mean interval of 50 months (range 10-96 months). NYHA functional class changed from II to III in six patients, from III to IV in 11, and from II to IV in three during this period. No class change occurred in the remaining 25 patients (eight male and 17 female, mean age 32 years, range 15 to 58: no change group); these were

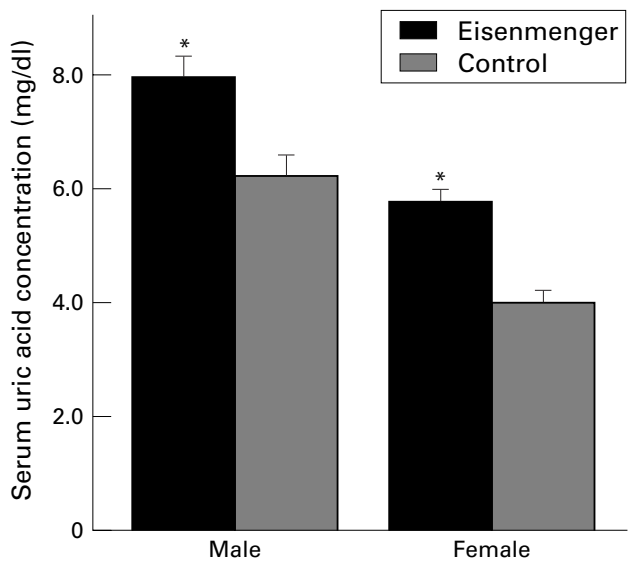

Figure 1 Serum uric acid in male and female adult patients with Eisenmenger syndrome compared with age matched control subjects. Values are means, error bars $=$ SEM. ${ }^{\star} p<0.0001$ v control.

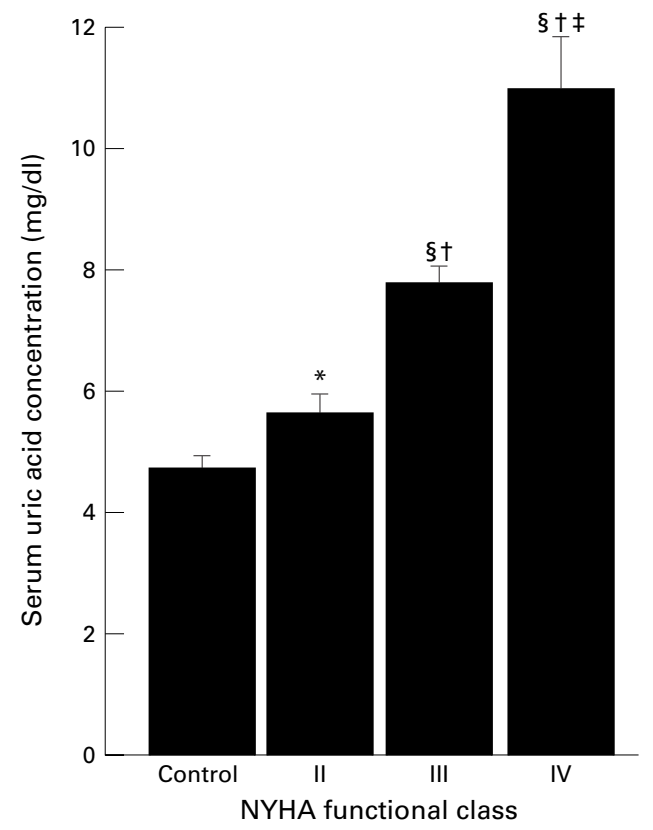

Figure 2 Serum uric acid concentration in adult patients with Eisenmenger syndrome according to NYHA functional class. Values are means, error bars $=$ SEM. Scheffé's multiple comparison test: ${ }^{\star} p=0.0103 v$ controls; $\int_{p}<0.0001 v$ controls; $t p<0.0001 v$ NYHA class II; $\neq p<0.0001 v$ NYHA class III. 


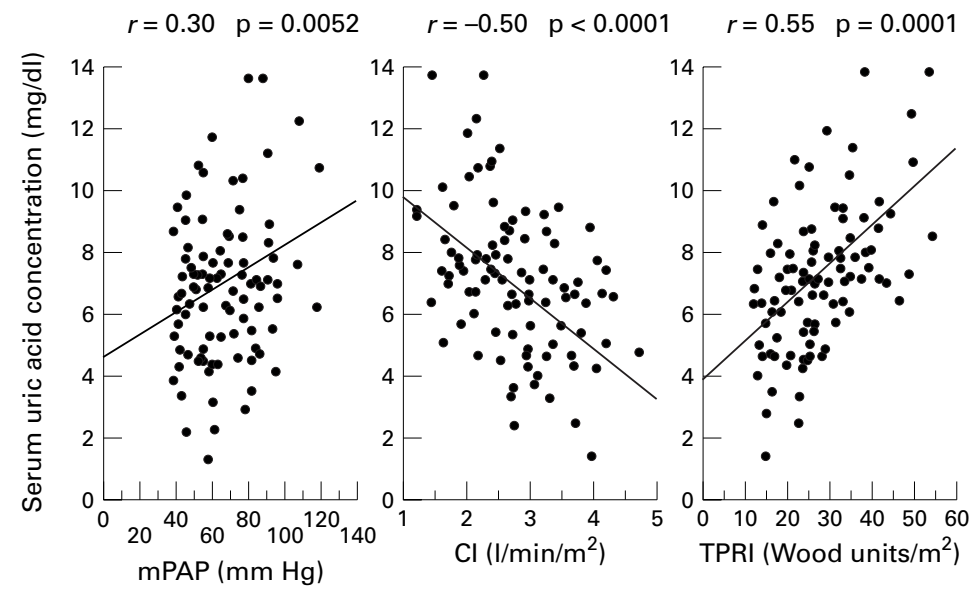

Figure 3 Relation between the serum uric acid concentration and mean pulmonary arterial pressure (mPAP, left panel), cardiac index (CI, middle panel), and total pulmonary resistance index (TPRI, right panel) in adult patients with Eisenmenger syndrome.

re-evaluated after a mean of 41 months (range 14 to 94 months).

ECHOCARDIOGRAPHIC ASSESSMENT

Doppler echocardiography was performed in 74 patients with a Toshiba SSH-1204A and $2.5 \mathrm{MHz}$ sector transducer (Toshiba Co, Tokyo, Japan) in the standard apical four chamber view, optimised to obtain the longest right ventricular long axis. The largest short axis diameters were acquired at the base and mid-ventricular level at the greatest visualised excursion of the tricuspid leaflets. The maximum transtricuspid pressure gradient was estimated by continuous wave Doppler using a modified Bernoulli equation. ${ }^{23}$

\section{SURVIVAL ANALYSIS}

Survival was tracked from the date of the first uric acid sampling to 31 October 1998, or to the death of the patient from cardiopulmonary causes. Five patients who died of noncardiopulmonary causes (two from pregnancy related causes, two from malignant disease (hepatoma and myelodysplastic syndrome), and one of non-cardiac surgery (after lung biopsy) were censored at the time of death. No patient underwent cardiac transplantation during the follow up period.

Table 2 Multivariate analysis of variables associated with serum uric acid concentration in adult patients with Eisenmenger syndrome

\begin{tabular}{lcc}
\hline Variables & $\begin{array}{l}\text { Standardised } \\
\text { coefficient }\end{array}$ & p Value \\
\hline Age & -0.077 & 0.3979 \\
Sex & 0.691 & 0.0848 \\
BMI & 0.086 & 0.3358 \\
Drinking & -0.027 & 0.7503 \\
mSAP & 0.027 & 0.7491 \\
mPAP & 0.092 & 0.3652 \\
Cardiac index & -0.325 & 0.0016 \\
Arterial oxygen saturation & -0.171 & 0.0845 \\
Packed cell volume & 0.076 & 0.4966 \\
Mean corpuscular volume & -0.092 & 0.3844 \\
Serum creatinine & 0.334 & 0.0019 \\
Serum total cholesterol & 0.007 & 0.9395 \\
Serum triglycerides & 0.077 & 0.3687 \\
Fasting blood glucose & -0.108 & 0.2249 \\
Diuretic treatment & 0.087 & 0.3493 \\
Venesections & 0.068 & 0.4420
\end{tabular}

For abbreviations see table 1
STATISTICAL ANALYSIS

Numerical values are expressed as mean (SEM). Comparisons of variables between two groups were made by Fisher's exact test or the unpaired Student $t$ test. Comparison of serial uric acid values was performed with a paired $t$ test. Serum uric acid concentrations between multiple groups were compared using one way analysis of variance, followed by Scheffés multiple comparison test. Correlation coefficients between serum uric acid concentration and haemodynamic or laboratory variables were calculated by Pearson's product moment correlation coefficient. Categorical data were assessed using a $\chi^{2}$ test. Multivariate regression analysis was performed to determine the independent association of clinical variables with serum uric acid level. The prognostic value of each variable was tested by univariate Cox proportional hazard regression analysis. The independent association of serum uric acid concentration with survival was tested by multivariate Cox proportional hazard regression analysis. Survival curves grouped to the median value of uric acid were derived using the Kaplan-Meier method and compared using the log-rank test.

\section{Results}

PATIENT CHARACTERISTICS ACCORDING TO SURVIVAL

During a mean (SEM) follow up period of 97 (6) months, 38 patients died of cardiopulmonary causes: 19 died suddenly, 17 died of heart failure, one died of haemoptysis, and one died from infectious endocarditis. There was no significant difference between survivors and nonsurvivors in age, sex, body mass index, serum total cholesterol, serum triglycerides, fasting blood glucose, or shunt lesion (table 1). NYHA functional class differed significantly between survivors and non-survivors. Mean pulmonary arterial pressure, total pulmonary resistance index, and right atrial pressure were significantly higher in non-survivors than in survivors. Cardiac index, arterial oxygen saturation, and mixed venous oxygen saturation were lower in non-survivors than in survivors. Serum creatinine concentration was significantly higher in non-survivors than in survivors. Diuretics were used more often in non-survivors than in survivors. Venesection was performed more often in non-survivors than in survivors.

SERUM URIC ACID AND CLINICAL VARIABLES Serum uric acid concentration was significantly raised in adult patients with Eisenmenger syndrome of either sex compared with the controls (fig 1), and increased in proportion to the severity of NYHA functional class (fig 2). Serum uric acid concentration correlated positively with serum creatinine concentration $(r=0.49, \mathrm{p}<0.0001)$ and packed cell volume $(r=0.45, \mathrm{p}<0.0001)$, and negatively with arterial oxygen saturation $(r=-0.41$, $\mathrm{p}<0.0001)$ and mixed venous oxygen saturation $(r=-0.39, \mathrm{p}=0.0010)$. There was no significant difference in serum uric acid concentration between the various shunt lesion groups (atrial septal defect $6.7(0.3) \mathrm{mg} / \mathrm{dl}$, 
Table 3 Univariate predictors of mortality in patients with Eisenmenger syndrome

\begin{tabular}{llll}
\hline Variables & $\begin{array}{l}\text { Risk ratio } \\
\text { estimate }\end{array}$ & $95 \%$ CI & p Value \\
\hline Age & 0.995 & 0.970 to 1.022 & 0.7285 \\
Male sex & 1.626 & 0.879 to 3.008 & 0.1213 \\
NYHA functional class & 2.478 & 1.588 to 3.867 & 0.0014 \\
Presence of syncope & 2.807 & 1.245 to 6.331 & 0.0129 \\
Presence of haemoptysis & 0.507 & 0.121 to 2.117 & 0.3512 \\
Haemodynamic variables & & & \\
$\quad$ mSAP & 0.980 & 0.949 to 1.013 & 0.2346 \\
mPAP & 1.011 & 0.995 to 1.026 & 0.1756 \\
Cardiac index & 0.347 & 0.201 to 0.599 & 0.0010 \\
TPRI & 1.063 & 1.003 to 1.094 & 0.0001 \\
$\quad$ Right atrial pressure & 1.103 & 1.036 to 1.174 & 0.0020 \\
$\quad$ PCWP & 1.022 & 0.951 to 1.097 & 0.5563 \\
Arterial oxygen saturation & 0.919 & 0.875 to 0.966 & 0.0008 \\
Transtricuspid pressure gradient & 1.011 & 0.992 to 1.029 & 0.2571 \\
Packed cell volume & 1.037 & 0.991 to 1.085 & 0.1140 \\
Serum uric acid & 1.498 & 1.306 to 1.719 & 0.0001 \\
Serum creatinine & 2.962 & 1.106 to 8.096 & 0.0310 \\
\hline
\end{tabular}

For abbreviations see table 1 .

Table 4 Multivariate predictors of mortality in patients with Eisenmenger syndrome

\begin{tabular}{llll}
\hline Non-invasive variables & $\begin{array}{l}\text { Risk ratio } \\
\text { estimate }\end{array}$ & $95 \%$ CI & p Value \\
\hline Age (decade) & 0.964 & 0.522 to 1.784 & 0.9082 \\
Male sex & 1.911 & 0.580 to 6.299 & 0.2871 \\
BMI & 0.849 & 0.656 to 1.099 & 0.2134 \\
NYHA functional class & 1.992 & 0.711 to 5.583 & 0.1898 \\
mSAP & 0.998 & 0.943 to 1.056 & 0.9333 \\
Presence of syncope & 2.263 & 0.862 to 12.352 & 0.0816 \\
Presence of haemoptysis & 1.540 & 0.269 to 8.818 & 0.6276 \\
Transtricuspid pressure gradient & 1.009 & 0.973 to 1.046 & 0.6470 \\
Arterial oxygen saturation & 1.037 & 0.946 to 1.137 & 0.4433 \\
Packed cell volume & 0.954 & 0.896 to 1.015 & 0.1342 \\
Serum uric acid & 1.614 & 1.344 to 2.727 & 0.0014 \\
Serum creatinine & 0.146 & 0.019 to 1.135 & 0.0659 \\
Serum total cholesterol & 0.991 & 0.977 to 1.005 & 0.2175 \\
Fasting blood glucose & 1.026 & 0.981 to 1.072 & 0.2672 \\
Diuretic treatment & 1.849 & 0.589 to 5.807 & 0.2922 \\
Venesections & 0.455 & 0.711 to 2.067 & 0.3079 \\
\hline
\end{tabular}

For abbreviations see table 1 .

ventricular septal defect $6.6(0.4) \mathrm{mg} / \mathrm{dl}$, persistent arterial duct $7.3(0.3) \mathrm{mg} / \mathrm{dl}$, others 7.1 (0.7) $\mathrm{mg} / \mathrm{dl}$; Scheffé's multiple comparison test: all $\mathrm{p}>0.05)$. Among the 38 nonsurvivors, serum uric acid concentrations were similar in those treated with and without diuretics $(8.6 \quad(0.6) \quad v \quad 8.7 \quad(0.5) \mathrm{mg} / \mathrm{dl}$, $\mathrm{p}=0.8497)$.

SERIAL URIC ACID VALUES

Serum uric acid concentration was significantly increased from baseline in the exacerbation group (from $7.0(0.1)$ to $8.4(0.6) \mathrm{mg} / \mathrm{dl}$, $\mathrm{p}=0.0002)$. In contrast, serum uric acid did not change significantly in the no change group (from $6.7(0.4)$ to $6.9 \quad(0.4) \mathrm{mg} / \mathrm{dl}$, $\mathrm{p}=0.1843)$.

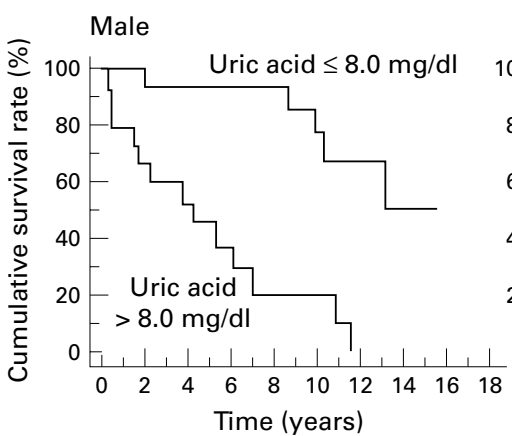

\section{Female}

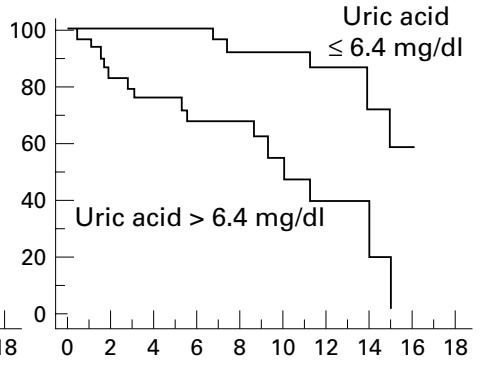

Time (years)

Figure 4 Kaplan-Meier analysis of cumulative survival rates in patients with Eisenmenger syndrome according to the median serum uric acid concentration. Log-rank test: $p=0.0014$ in male patients; $p=0.0034$ in female patients.
SERUM URIC ACID AND HAEMODYNAMIC

VARIABLES

Serum uric acid concentration correlated positively with mean pulmonary arterial pressure $(r=0.30, \mathrm{p}=0.0052$, fig 3$)$ and negatively with cardiac index $(r=-0.50, \mathrm{p}<0.0001)$. Accordingly, serum uric acid concentration increased significantly in proportion to total pulmonary resistance index $(r=0.55$, $\mathrm{p}<0.0001)$. Serum uric acid concentration did not correlate significantly with mean systemic arterial pressure or pulmonary capillary wedge pressure.

In multivariate regression analysis, serum uric acid concentration was related to cardiac index and serum creatinine but was independent of all other factors examined (table 2).

SERUM URIC ACID AND MORTALITY

Serum uric acid concentration was significantly higher in non-survivors than in survivors, and it tended to be higher in patients who died suddenly than in those who died of heart failure $(9.5 \quad(0.6) \quad v \quad 8.0 \quad(0.5) \mathrm{mg} / \mathrm{dl}$, $\mathrm{p}=0.3600)$. Univariate Cox proportional hazard analysis showed that serum uric acid, NYHA functional class, presence of syncope, cardiac index, total pulmonary resistance index, right atrial pressure, and arterial oxygen saturation were significantly related to mortality (table 3). Multivariate analysis showed that serum uric acid remained predictive of survival rate in the presence of other noninvasive variables, listed in table 4 .

Owing to significant sex differences in serum uric acid concentrations, ${ }^{24}$ median values were broken down by sex in the analysis (male subjects $8.0 \mathrm{mg} / \mathrm{dl}$; female subjects $6.4 \mathrm{mg} / \mathrm{dl})$. Kaplan-Meier survival curves related to median serum uric acid value and sex showed that patients with a high serum uric acid had a significantly reduced survival rate compared with those with a low serum uric acid (log-rank test, $\mathrm{p}=0.0014$ in male patients; $\mathrm{p}=0.0034$ in female patients, fig 4 ).

\section{Discussion}

In this study, we showed first, that serum uric acid concentration increased significantly in proportion to the severity of NYHA functional class in adult patients with Eisenmenger syndrome; second, that serum uric acid correlated positively with mean pulmonary arterial pressure and total pulmonary resistance index, and negatively with cardiac index; third, that among non-invasive variables, serum uric acid was an independent predictor of mortality by multivariate analysis; and fourth, that patients with a high serum uric acid concentration had a significantly worse survival rate than those with a low serum uric acid concentration, based on Kaplan-Meier survival curves for median serum uric acid values and sex.

RAISED SERUM URIC ACID IN EISENMENGER SYNDROME

We found that serum uric acid was increased in patients with Eisenmenger syndrome compared with age and sex matched controls, as in previous studies. ${ }^{25}{ }^{26}$ Ross and colleagues have 
shown that hyperuricaemia in cyanotic congenital heart disease is attributable to enhanced urate reabsorption secondary to abnormal intrarenal haemodynamics. ${ }^{26}$ An increase in lactate in hypoxic states has also been shown to inhibit tubular uric acid secretion. ${ }^{27}$ In the present study, serum uric acid was independently correlated with cardiac index and serum creatinine in multivariate analysis. These results raise the possibility that reduced excretion of uric acid because of impaired intrarenal dynamics contributes to hyperuricaemia in Eisenmenger syndrome.

Alternatively, overproduction of uric acid could be responsible for increased serum uric acid in these patients. Earlier studies have shown that tissue ischaemia exhausts adenosine triphosphate (ATP) and activates the purine nucleotide degradation pathway to uric acid, resulting in overproduction of uric acid in the heart, lung, liver, and skeletal muscle. ${ }^{71028}{ }^{29}$ Uric acid production has indeed been shown to increase in proportion to the severity of hypoxia in patients with chronic obstructive pulmonary disease and obstructive sleep apnea. ${ }^{9}{ }^{10}$ As we found negative correlations between serum uric acid and cardiac index, arterial oxygen saturation, and mixed venous oxygen saturation, it is possible that tissue hypoxia may induce overproduction of uric acid in a variety of organs in patients with Eisenmenger syndrome.

We found no significant difference in serum uric acid concentration according to the various types of shunt lesion, although patients with a persistent arterial duct tended to have a greater increase than those with other shunt lesions. Further studies are needed to determine whether the haemodynamic differences associated with various shunt lesions may indirectly affect serum uric acid in patients with Eisenmenger syndrome.

Hyperlipidaemia, diabetes mellitus, hypertension, and obesity have been shown to be related to hyperuricaemia. ${ }^{16-20}$ However, using multivariate analysis we showed that serum uric acid concentration was not independently correlated with body mass index, systemic arterial pressure, serum total cholesterol, serum triglycerides, or fasting blood glucose. Most of our patients were young, so the prevalence of these risk factors was quite low. Thus we can assume that they would have had little influence on serum uric acid in our study population. Diuretic treatment is also known to affect serum uric acid metabolism. ${ }^{30}$ However, among the 38 non-survivors, serum uric acid concentration in patients treated with diuretics was similar to that in patients with no diuretic treatment. In addition, there was no independent correlation between serum uric acid and diuretic treatment. Diuretic use may therefore not be a major contributor to the rise in serum uric acid in adult patients with Eisenmenger syndrome. This is consistent with previous reports of serum uric acid in patients with heart failure ${ }^{67}$ and primary pulmonary hypertension. ${ }^{15}$
SERUM URIC ACID AND MORTALITY

Earlier studies have shown that the presence of right ventricular dysfunction, increased right atrial pressure, syncope, reduced arterial oxygen saturation, and increased serum creatinine are associated with increased mortality in patients with Eisenmenger syndrome. ${ }^{325}$ However, pulmonary artery catheterisation is associated with complications ${ }^{31}$ that may be life threatening for patients with Eisenmenger syndrome. A non-invasive and easily repeatable assessment of mortality risk would be very useful. We therefore included non-invasive variables in a multivariate Cox proportional hazards analysis. Serum uric acid concentration has recently been shown to have a strong, independent association with long term mortality rate in patients with heart failure ${ }^{13}{ }^{14}$ and primary pulmonary hypertension ${ }^{15}$; however, whether it is also predictive of mortality in Eisenmenger syndrome has so far not been determined. In the present study, among several other non-invasive variables serum uric acid remained predictive in multivariate analysis in our adult patients with Eisenmenger syndrome. The close relations between serum uric acid and right ventricular haemodynamic variables, hypoxia, and serum creatinine may explain the significant prognostic value of serum uric acid. A rise in uric acid could reflect organ injury induced by impaired oxidative metabolism and thereby correlate with a poor outcome in these patients.

In this study, death during follow up was usually sudden, as was found in earlier studies. ${ }^{2} 3$ Serum uric acid concentration was notably high in such patients. Harrison and colleagues have shown that ventricular dysfunction poses a significant risk of sudden death in adult patients with congenital heart disease. ${ }^{32}$ Along with a negative correlation between serum uric acid and cardiac index, measurement of serum uric acid concentration may be helpful in predicting sudden death in patients with Eisenmenger syndrome.

CLINICAL IMPLICATIONS

Serum uric acid can be measured routinely and inexpensively, and may serve as an indicator of disease severity in adult patients with Eisenmenger syndrome. Moreover, serum uric acid measurement can be performed repeatedly as a predictor of mortality in the long term follow up of adult patients with this syndrome.

\section{STUDY LIMITATIONS}

First, patients with renal failure were excluded from the study because such patients will have a rise in serum uric acid secondary to their renal failure ${ }^{33}$; thus measurement of their serum uric acid is unlikely to be useful for evaluating disease severity. Second, serum concentrations of iron and ferritin, and transferrin saturation, were not assessed, so iron deficiency anaemia could not be excluded in this study. However, there was no significant difference in the baseline values of mean corpuscular volume between survivors and non-survivors. Further studies are needed to determine whether iron deficiency anaemia affects serum 
uric acid or mortality in adult patients with Eisenmenger syndrome. Third, drug useincluding digitalis, vasodilators, and anticoagulant agents-was not controlled in our study. However, there was no significant difference between survivors and non-survivors in their baseline drug treatment. Further studies are needed to evaluate the relation between repeated measurements of serum uric acid and the effect of treatment with various drugs in adult patients with Eisenmenger syndrome.

CONCLUSIONS

Serum uric acid concentration increases in proportion to haemodynamic compromise and is independently associated with long term mortality in adult patients with Eisenmenger syndrome.

We thank Nobuo Shirahashi for his statistical advice. This work was supported in part by the Japan Heart Foundation Research Grant.

1 Wood P. The Eisenmenger syndrome or pulmonary hypertension with reversed central shunt. BMF 1958; ii: $755-2$

2 Young D, Mark H. Fate of the patient with the Eisenmenger syndrome. Am f Cardiol 1971;28:658-69.

3 Saha A, Balakrishnan KG, Jaiswal PK, et al. Prognosis for patients with Eisenmenger syndrome of various aetiology. Int $\mathcal{F}$ Cardiol 1994;45:199-207.

4 Hopkins WE, Ochoa LL, Richardson GW, et al. Comparison of the haemodynamics and survival of adults with severe primary pulmonary hypertension or Eisenmenger syndrome. I Heart Lung Transplant 1996;15:100-5.

5 Wanpen V, Bricker ME, Hills LD, et al. The Eisenmenger syndrome in adults. Ann Intern Med 1998;128:745-55.

6 Leyva F, Anker S, Swan JW, et al. Serum uric acid as an index of impaired oxidative metabolism in chronic heart index of impaired oxidative metabolisn

7 Anker SD, Leyva F, Poole-Wilson PA, et al. Relation Anker SD, Leyva F, Poole-Wilson PA, et al. Relation
between serum uric acid and lower limb blood flow in between serum uric acid and lower limb blood flow in
patients with chronic heart failure. Heart 1997;78:39-43.

patients with chronic heart failure. Heart 1997;78:39-43.
8 Hayabuchi Y, Matsuoka S, Akita H, et al. Hyperuricaemia in cyanotic congenital heart disease. Eur $\mathcal{F}$ Pediatr 1993;152: $873-6$

9 Braghiroli A, Sacco C, Erbetta M, et al. Overnight urinary uric acid:creatinine ratio for detection of sleep hypoxemia. Validation study in chronic obstructive pulmonary disease and obstructive sleep apnea before and after treatment with nasal continuous positive airway pressure. Am Rev Respir Dis 1993;148:173-8.

10 Elsayed NM, Nakashima JM, Postlehwait EM. Measurement of uric acid as a maker of oxygen tension in the lung. Arch Biochem Biophys 1993;302:228-32.

11 Hasday JD, Grum CM. Noctunal increase of urinary uric acid:creatinine ratio: a biochemical correlate of sleep associated hypoxemia. Am Rev Respir Dis 1987;135:534-8.
12 Laurence HB. Clinical disorders of uric acid metabolism. Med Clin North Am 1981;65:401-11.

13 Anker SD, Leyva F, Poole-Wilson PA, et al. Uric acid as independent predictor of impaired prognosis in patients with chronic heart failure [abstract]. $\mathcal{F} \mathrm{Am}$ Coll Cardiol 1998;31:154A.

14 Woolliscroft JO, Colfer H, Fox IH. Hyperuricemia in acute illness: a poor prognostic sign. Am f Med 1982;72:58-62.

15 Nagaya N, Uematsu M, Satoh T, et al. Serum uric acid levels correlate with the severity and the mortality of primary pulmonary hypertension. Am Respir Crit Care Med 1999;160:487-92.

16 Messerli F, Frochlich E, Dreslinski G. Serum uric acid in essential hypertension: an indicator of renal vascular involvement. Ann Intern Med 1980;93:817-21.

17 Berkowitz D. Blood lipid and uric acid interrelationships. 7AMA 1966;190:856-8.

18 Friedman E, Wallance S. Hypertriglycemia in gout. Circulation 1964;29:508-11.

19 Herman JB, Gouldbourt U. Uric acid and diabetes: observations in a population study. Lancet 1988;ii:240-3.

20 Facchini F, Chen YD, Hollenbeck CB, et al. Relationship between resistance to insulin-mediated glucose uptake, urinary uric acid clearance, and plasma uric acid concentration. $7 A M A$ 1991;266:3008-11.

21 Antman EM, Marsh JD, Green LH, et al. Blood oxygen measurements in the assessment of intracardiac left to right shunts: a critical appraisal of methodology. Am 7 Cardiol 1980;46:265-71.

22 Domak GF, Schlickle HH. A colorimetric method using uricase and peroxidase for the determination of uric acid. Anal Biochem 1968;22:219-24.

23 Philip JC, James BS, Kwan-Leung C, et al. Continuous wave Doppler determination of right ventricular pressure: a simultaneous Doppler-catheterization study in 127 patients. F Am Coll Cardiol 1985;6:750-6.

24 Akizuki S. Serum uric acid levels among thirty-four thousand people in Japan. Ann Rheum Dis 1982;41:272-4.

25 Daliento L, Somerville J, Presbitero P, et al. Eisenmenger syndrome. Factors relating to deterioration and death. Eur Heart 7 1998; 19:1845-55.

26 Ross EA, Perloff JK, Danovitch GM, et al. Renal function and urate metabolism in late survivors with cyanotic congenital heart disease. Circulation 1986;73:396-400.

27 Emmerson BT, Ravenscroft PJ. Abnormal renal urate homeostasis in systemic disorders. Nephron 1975;14:6280 .

28 Huizer T, de Jong JW, Nelson JA, et al. Urate production by human heart. $7 \mathrm{Mol}$ Cell Cardiol 1989;21:691-5.

$29 \mathrm{McCord} J M$. Oxygen-derived free radicals in relation to age and sex. F Pakistan Med Assoc 1980;30:242-4.

30 Darlington LG. Study to compare the relative hyperuricemic effects of frusemide and bumtamide. Adv Exp Med Biol 1986;195:333-9.

31 Chastre J, Cornud F, Bouchama A, et al. Thrombosis as a complication of pulmonary-artery catheterization via the internal jugular vein. $N$ Engl F Med 1982;281:278-81.

32 Harrison DA, Connelly M, Harris L, et al. Sudden cardiac death in the adult with congenital heart disease. Can f Cardiol 1996;12:1161-3.

33 Perloff JK. Systemic complications of cyanosis in adults with congenital heart disease. Haematologic derangements, renal function, and urate metabolism. Cardiol Clin 1993;11: 689-99. 